\title{
Diurnal rhythms in neural activation in the mesolimbic reward system: critical role of the medial prefrontal cortex
}

\author{
Ricardo M. Baltazar, ${ }^{1}$ Lique M. Coolen ${ }^{1,2,3}$ and Ian C. Webb ${ }^{4}$ \\ ${ }^{1}$ Department of Anatomy and Cell Biology, University of Western Ontario, London, ON, Canada \\ ${ }^{2}$ Department of Molecular \& Integrative Physiology, University of Michigan, Ann Arbor, MI, USA \\ ${ }^{3}$ Department of Physiology \& Biophysics, University of Mississippi Medical Center, Jackson, MS, USA \\ ${ }^{4}$ Department of Neurobiology and Anatomical Sciences, University of Mississippi Medical Center, 2500 North State St, Jackson, \\ MS, 39216-4505, USA
}

Keywords: c-Fos, circadian, excitotoxic lesion, rat, reward

\begin{abstract}
Previous evidence suggests a circadian modulation of drug-seeking behavior and responsiveness to drugs of abuse. To identify potential mechanisms for rhythmicity in reward, a marker of neural activation (cFos) was examined across the day in the mesolimbic reward system. Rats were perfused at six times during the day [zeitgeber times (ZTs): 2, 6, 10, 14, 18, and 22], and brains were analysed for cFos and tyrosine hydroxylase (TH)-immunoreactive (IR) cells. Rhythmic expression of cFos was observed in the nucleus accumbens (NAc) core and shell, in the medial prefrontal cortex (mPFC), and in TH-IR and non-TH-IR cells in the ventral tegmental area (VTA), with peak expression during the late night and nadirs during the late day. No significant rhythmicity was observed in the basolateral amgydala or the dentate gyrus. As the mPFC provides excitatory input to both the NAc and VTA, this region was hypothesised to be a key mediator of rhythmic neural activation in the mesolimbic system. Hence, the effects of excitotoxic mPFC lesions on diurnal rhythms in cFos immunoreactivity at previously observed peak (ZT18) and nadir (ZT10) times were examined in the NAc and VTA. mPFC lesions encompassing the prelimbic and infralimbic subregions attenuated peak cFos immunoreactivity in the NAc, eliminating the diurnal rhythm, but had no effect on VTA rhythms. These results suggest that rhythmic neural activation in the mesolimbic system may contribute to diurnal rhythms in reward-related behaviors, and indicate that the mPFC plays a critical role in mediating rhythmic neural activation in the NAc.
\end{abstract}

\section{Introduction}

Rewarding behaviors are largely mediated by the mesolimbic system (Wise, 2004; Frohmader et al., 2010a), composed of the ventral tegmental area (VTA), nucleus accumbens (NAc), medial prefrontal cortex (mPFC), amygdala, and other regions (Spanagel \& Weiss, 1999; Ikemoto, 2007). Mesolimbic brain areas are activated during natural reward behaviors (Noel \& Wise, 1995; Martel \& Fantino, 1996), including sexual behavior (Pfaus et al., 1990; Balfour et al., 2004; Frohmader et al., 2010b; Pitchers et al., 2010), aggression (Wolf et al., 2004), and maternal behavior (Champagne et al., 2004; Numan et al., 2010); and in response to conditioned cues predicting natural rewards (Balfour et al., 2004), and drugs of abuse (Di Chiara \& Imperato, 1988; Thomas et al., 2008). A growing body of work has revealed that many of the behavioral responses to rewarding stimuli vary substantially over the course of a day. Conditioned place preference, locomotor activation and sensitisation in response to psychostimulants (Abarca et al., 2002; Kurtuncu et al., 2004; Webb et al., 2009) and natural rewards (Webb et al., 2009) depend

Correspondence: Ian C. Webb, as above.

E-mail: iwebb@umc.edu

Received 24 January 2013, revised 26 February 2013, accepted 20 March 2013 significantly on the time of day. The mechanisms responsible for these diurnal rhythms in motivation and reward remain to be fully elucidated, but there is evidence for involvement of the mesolimbic system, and particularly for the neurotransmitter dopamine. Markers of dopaminergic activity vary by time of day in the VTA and NAc, including the expression of tyrosine hydroxylase (TH), the rate-limiting enzyme in dopamine synthesis (Sleipness et al., 2007; Webb et al., 2009), dopamine transporters (Sleipness et al., 2007), and monoamine oxidase (Hampp et al., 2008).

Here, we characterised diurnal fluctuations in neural activation throughout the mesocorticolimbic system, using cFos protein expression as the marker. The use of cFos to elucidate diurnal rhythms in neural activation is well documented for brain areas involved in sleep and wakefulness (Pompeiano et al., 1995; Bentivogolio, 1999), including activation of the orexin-hypocretin system (Estabrooke et al., 2001; Martinez et al., 2002). Moreover, investigation of cFos protein expression during sleep and awake states provided support for diurnal rhythms in neural activation in the mesolimbic system (Pompeiano et al., 1994). However, a comprehensive characterisation of neural activation in the mesolimbic system across the day has yet to be conducted.

We also tested the hypothesis that the mPFC plays a critical role in mediating the daily rhythms in neural activation in the mesolim- 
bic system. The mPFC provides a major source of glutamatergic inputs to the VTA and NAc (Carr \& Sesack, 1999, 2000; Balfour et al., 2006; Omelchenko \& Sesack, 2007), and glutamate receptor activation has been implicated in the induction of cFos expression (Xia et al., 1996; Rossetti et al., 1998; Vanhoutte et al., 1999; Dominguez et al., 2007). Therefore, the mPFC is a potential candidate for regulating diurnal rhythms in neural activation in its target areas.

\section{Materials and methods}

\section{Animals}

Young adult male Sprague-Dawley rats (300-350 g; Charles River Laboratories, Quebec, Canada) were pair-housed in standard rat housing cages with ad libitum food and water. The rats were placed under a $12: 12$-h light/dark cycle $(\sim 350$ lux light/0 lux dark), and were allowed to acclimatise and entrain to the light/ dark cycle for 2 weeks prior to tissue collection or surgery. All experiments were approved by the University of Western Ontario Animal Care Committee and the University Committee on Use and Care of Animals at the University of Michigan, and were performed in compliance with the guidelines of the Canadian Council on Animal Care and the United States National Institutes of Health.

\section{Tissue collection}

At six different zeitgeber times (ZTs) (ZT2, ZT6, ZT10, ZT14, ZT18, and ZT22, where ZT12 corresponds to lights off, by convention), rats ( $n=6-8$ per time point) were deeply anesthetised with intraperitoneal sodium pentobarbital $(270 \mathrm{mg} / \mathrm{kg})$ and perfused transcardially with $50 \mathrm{~mL}$ of saline followed by $500 \mathrm{~mL}$ of $4 \%$ paraformaldehyde in $0.1 \mathrm{~m}$ phosphate buffer (PB). Brains were removed, post-fixed for $1 \mathrm{~h}$, and stored in $20 \%$ sucrose in $0.1 \mathrm{M}$ PB with $0.01 \%$ sodium azide at $4{ }^{\circ} \mathrm{C}$ until sectioning. For time points coinciding with the dark phase, tissue collection was performed under dim red light ( $\sim 1$ lux). Brains were sectioned with a freezing microtome into four parallel series of $35-\mu \mathrm{m}$ coronal sections, and stored in cryopreservative (Watson et al., 1986) at $-20{ }^{\circ} \mathrm{C}$ until immunohistochemical processing.

\section{Immunohistochemistry}

All incubations and rinses were performed at room temperature on free-floating tissue with gentle agitation. Following each incubation, sections were rinsed thoroughly in phosphate-buffered saline (PBS) (0.1 M, pH 7.4). One series of brain sections from all experimental animals were stained simultaneously. The tissue was first incubated for $10 \mathrm{~min}$ in $1 \% \mathrm{H}_{2} \mathrm{O}_{2}$ in $0.1 \mathrm{M}$ PBS and for $1 \mathrm{~h}$ in incubation solution $[0.1 \%$ bovine serum albumin and $0.4 \%$ Triton X-100 (Fisher Scientific, Ottawa, Ontario, Canada) in PBS]. Next, the tissue was incubated with a rabbit polyclonal antibody specifically recognising cFos (1:7500 in incubation solution; 17 h; SC-52; Santa Cruz Biotechnology, Santa Cruz, CA, USA) followed by biotinylated donkey anti-rabbit $\operatorname{IgG}(1: 500$ in incubation solution; $1 \mathrm{~h}$; Jackson Immunoresearch Laboratories, West Grove, PA, USA) and avidin-biotin-horseradish peroxidase complex (ABC) $(1: 1000$ in PBS; $1 \mathrm{~h}$; ABC Elite Kit; Vector Laboratories, Burlingame, CA, USA). Antibody binding was visualised with diaminobenzidene (DAB) (Sigma-Aldrich, St Louis, MO, USA) solution $\left(0.01 \% \mathrm{DAB}, 0.012 \% \mathrm{H}_{2} \mathrm{O}_{2}\right.$ in $\left.0.1 \mathrm{M} \mathrm{PB}\right)$ contain- ing $0.08 \%$ nickel sulfate for $10 \mathrm{~min}$, resulting in a black reaction product. Sections were then washed with $\mathrm{H}_{2} \mathrm{O}_{2}$ (1\% in PBS; $10 \mathrm{~min}$ ), and incubated with a mouse monoclonal antibody against TH (1:400 000 in incubation solution; $17 \mathrm{~h}$; Chemicon International, Temecula, CA, USA), a biotinylated donkey antimouse $\operatorname{IgG}(1: 500$ in PBS; $1 \mathrm{~h}$; Jackson Immunoresearch), and ABC $(1: 1000$ in PBS; 1 h). TH immunoreactivity was visualised with DAB $\left(0.01 \%\right.$ DAB and $0.012 \% \quad \mathrm{H}_{2} \mathrm{O}_{2}$ in $\mathrm{PB}(0.1 \mathrm{M}$; $10 \mathrm{~min}$ ), resulting in a brown reaction product (Fig. 2). Finally, sections were thoroughly rinsed in $\mathrm{PB}$, mounted on plus-charged slides (Fisher Scientific), dehydrated in alcohol, cleared with Citrisolv (Fisher Scientific), and coverslipped with di- $N$-butyl phthalate in xylene (Electron Microscopy Sciences, Fort Washington, PA, USA). The cFos antibody has been extensively validated, and results in a single band at the appropriate mass on western blot.

\section{Cell counting and analysis}

cFos-immunoreactive (IR) neurons in reward-related brain areas were counted in one or two sections per rat, with standard areas of analysis determined in accordance with previously defined landmarks (Swanson, 1998) (Fig. 1). The areas were as follows: the NAc core $(400 \times 600 \mu \mathrm{m})$ and shell $(400 \times 600 \mu \mathrm{m})$; the anterior cingulate area (ACA) $(400 \times 600 \mu \mathrm{m})$, the infralimbic (IL) $(400 \times 600 \mu \mathrm{m})$ and the prelimbic $(\mathrm{PL})(400 \times 600 \mu \mathrm{m})$ regions of the mPFC; the central amygdala $(\mathrm{CeA}) 400 \times 400 \mu \mathrm{m})$ and basolateral amygdala $(\mathrm{BLA})(600 \times 400 \mu \mathrm{m})$; and the dentate gyrus (DG) $(1800 \times 1200 \mu \mathrm{m})$. For each rat, counts were averaged to derive the mean number of cFos cells per unilateral structure. In the VTA $(900 \times 600 \mu \mathrm{m})$, cFos-IR, TH-IR and dual-labeled neurons were counted in two sections at the rostral-middle level (Balfour et al., 2004). More caudal levels of the VTA were not included, as no cFos expression was noted at any time points. Counts of cFos-IR cells in the suprachiasmatic nucleus (SCN) $(400 \times 400 \mu \mathrm{m})$ in two sections were performed as a positive control for circadian activation rhythms (Schwartz et al., 2000). Cell counts were carried out by two observers blinded to the experimental groups, using a Leica DMR microscope (Leica Microsystems, Wetzlar, Germany) with a camera lucida drawing tube.

\section{Statistical analysis}

One-way ANOVA followed by Newman-Keuls comparisons, KruskalWallis ANOVA followed by Dunn's comparisons or independent $t$-tests were utilised, where appropriate, to examine time-of-day effects. To confirm diurnal rhythmicity, data were also analysed with CIRCWAVE software (v. 1.4, courtesy of R. Hut; http://www. euclock.org). CIRCWAVE uses harmonic regression to fit a sinusoidal curve to the data and to test its significance against a fitted horizontal line.

\section{mPFC lesion surgery and verification}

Rats were anesthetised with intraperitoneal ketamine $(87 \mathrm{mg} / \mathrm{mL} /$ $\mathrm{kg}$ ) and intraperitoneal xylazine $(13 \mathrm{mg} / \mathrm{mL} / \mathrm{kg})$, and placed in a stereotaxic apparatus (Kopf Instruments, Tujunga, CA, USA). The skull was exposed, and two small burr holes were drilled at the following coordinates relative to bregma: anterior-posterior, $+2.9 \mathrm{~mm}$; medial-lateral, $\pm 0.6 \mathrm{~mm}$. A $5-\mu \mathrm{L}$ Hamilton Syringe (Hamilton, Reno, NV, USA) was used to bilaterally infuse ibotenic acid (2\% in $0.1 \mathrm{M}$ PBS; Sigma-Aldrich) or vehicle at two 


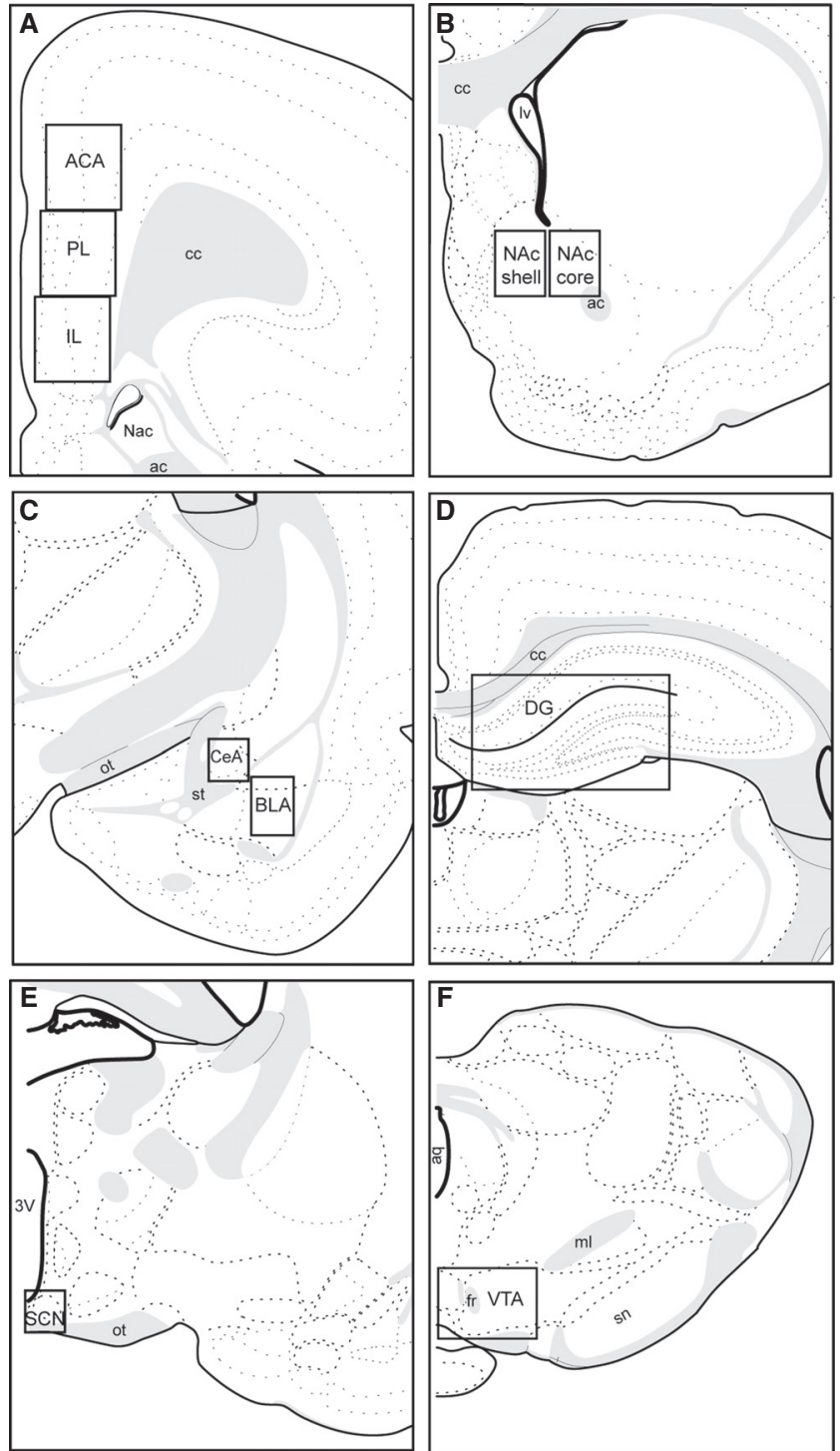

FIG. 1. Areas of analyses for cell counts. Schematic representations of areas of analyses in: (A) the ACA, IL and PL regions of the mPFC; (B) the NAc core and shell; (C) the CeA and BLA; (D) the DG; (E) the SCN; and (F) the VTA. ac, anterior commissure; aq, cerebral aqueduct; cc, corpus callosum; fr, fasciculus retroflexus; lv, lateral ventricle; ml, medial lemniscus; ot, optic tract; sn, substantia nigra; st, stria terminalis; $3 \mathrm{~V}$, third ventricle. Drawings modified from Swanson (1998).

dorsal-ventral coordinates corresponding to the IL and PL regions of the mPFC (from the top of skull, -5.0 and $-2.5 \mathrm{~mm} ; 0.25 \mu \mathrm{L}$ per $1 \mathrm{~min}$ per injection). The needle was left in place for $3 \mathrm{~min}$ following each injection, to allow for adequate diffusion. Rats were allowed 2 weeks to recover from surgery prior to tissue collection.

Sham-lesioned and mPFC-lesioned rats were perfused at two different time points, ZT10 and ZT18, corresponding, respectively, to nadirs and peaks in cFos immunoreactivity. One series of brain sections containing the NAc core and shell and the rostral and middle VTA from all sham-operated and lesioned rats were processed simultaneously for cFos immunoreactivity, and analysed as described above. The location and size of the lesions were determined by examining the area in cFos-immunostained mPFC sections showing tissue damage and lack of staining. Lesions of the $\mathrm{mPFC}$ typically spanned a distance from anterior to posterior of $+4.85 \mathrm{~mm}$ to $+1.70 \mathrm{~mm}$ relative to bregma, and encompassed the entire IL region and the majority of the PL region (ZT10, $n=6$; ZT18, $n=8$ ). Sham-operated rats did not have any damage (ZT10, $n=6$; ZT18, $n=4)$.

\section{Statistical analysis}

Two-way ANOVAs followed by Bonferroni comparisons or independent $t$-tests were used to assess lesion and time-of-day effects.

\section{Results}

\section{Rhythmic neural activation in the mesolimbic reward system}

A significant diurnal rhythm in the number of cFos-IR cells was observed in the NAc core (ANOVA, $K_{5}=22.99, P=0.0003$; CIRCWAVE, $F_{4,35}=10.11, P<0.0001$ ) and shell (ANOvA, $K_{5}=27.57$, $P<0.0001$; CIRCWAVE, $F_{4,35}=10.54, P<0.0001$; Figs $2 \mathrm{C}$ and $\mathrm{D}$ and 3), in all three subregions of the mPFC [ACA (ANOvA, $K_{5}=20.73, P=0.0009 ;$ CIRCWAVE, $\left.F_{4,38}=8.87, P<0.0001\right)$, PL (ANOVA, $\quad K_{5}=18.78, \quad P=0.0021 ; \quad$ CIRCWAVE, $\quad F_{4,38}=7.19$, $P=0.0002$ ), and IL (ANOva, $K_{5}=13.70, P=0.0177$; CIRCWAVE, $F_{2,40}=3.29, P=0.048$ ); Figs $2 \mathrm{~A}$ and $\mathrm{B}$ and 4$]$, and in the VTA (ANOVA, $\quad K_{5}=23.99, \quad P=0.0002 ; \quad$ CIRCWAVE, $\quad F_{2,33}=22.56$, $P<0.0001$; Figs $2 \mathrm{E}$ and $\mathrm{F}$ and $5 \mathrm{~A}$ ). In general, rhythms in the NAc, mPFC and VTA were similar in phase, with peaks during the night and nadirs during the late day. In the NAc core and shell, cFos expression had a nadir at ZT6-10 and peaks at ZT18-22 (Fig. 3). Within the subregions of the mPFC, cFos expression had a nadir at ZT10 (ACA and IL region) or ZT6-10 (PL region) and a peak at ZT18 (IL and PL regions) or ZT14-18 (ACA; Fig. 4). In the VTA, cFos expression had a nadir at ZT10 and peaks at ZT1822 (Fig. 5A).

The number of VTA TH-IR cells co-expressing cFos also showed a diurnal rhythm (ANOVA, $F_{5,30}=34.27, P<0.001$; CIRCwave, $F_{4,31}=28.82, P<0.0001$; Figs $2 \mathrm{E}$ and $\mathrm{F}$ and $5 \mathrm{C}$ ), with a nadir at ZT10 and peaks at ZT18-22. Moreover, at the peak time (ZT18), $18.8 \% \pm 1.8 \%$ of total VTA TH-IR cells also expressed cFos, and $23.8 \% \pm 3.9 \%$ of cFos-IR cells expressed TH (Fig. 5D). The number of TH-IR cells also varied over the day $\left(F_{5,35}=4.68, P=0.003\right)$, but in an ultradian fashion. Multiple peaks were observed at ZT6, ZT14, and ZT22, and a nadir at ZT10 (Fig. 5B).

In contrast, no diurnal rhythms in the numbers of cFos-IR cells were observed in the BLA or the DG (Fig. 6A and C). A marginal diurnal rhythmicity was observed in the CeA (CIRCWAVE, $F_{2,39}=3.25, P=0.049$; Fig. $6 \mathrm{~B}$ ), and ANOvA failed to detect significant differences between different time points (ANOvA, $F_{5,36}=2.19$, $P=0.076$ ). Finally, consistent with previous reports (Schwartz et al., 2000), the number of SCN cFos-IR cells was significantly greater at ZT6 than at ZT18 $(P=0.0022$; Fig. 6D).

\section{mPFC lesions attenuate rhythmic neural activation in the NAC without influencing the VTA}

mPFC lesions altered cFos rhythms in the NAc shell and core (Figs 7A and $\mathrm{B}$ and 8), but not in the VTA (Fig. 7C). In the NAc, mPFC lesions had a significant effect on the numbers of cFos-IR cells in both the core $\left(F_{1,19}=22.25, P=0.0002\right)$ and the shell $\left(F_{1,19}=22.57, P=0.0001\right)$. Moreover, significant interactions were found between time of day and lesion status for the NAc 

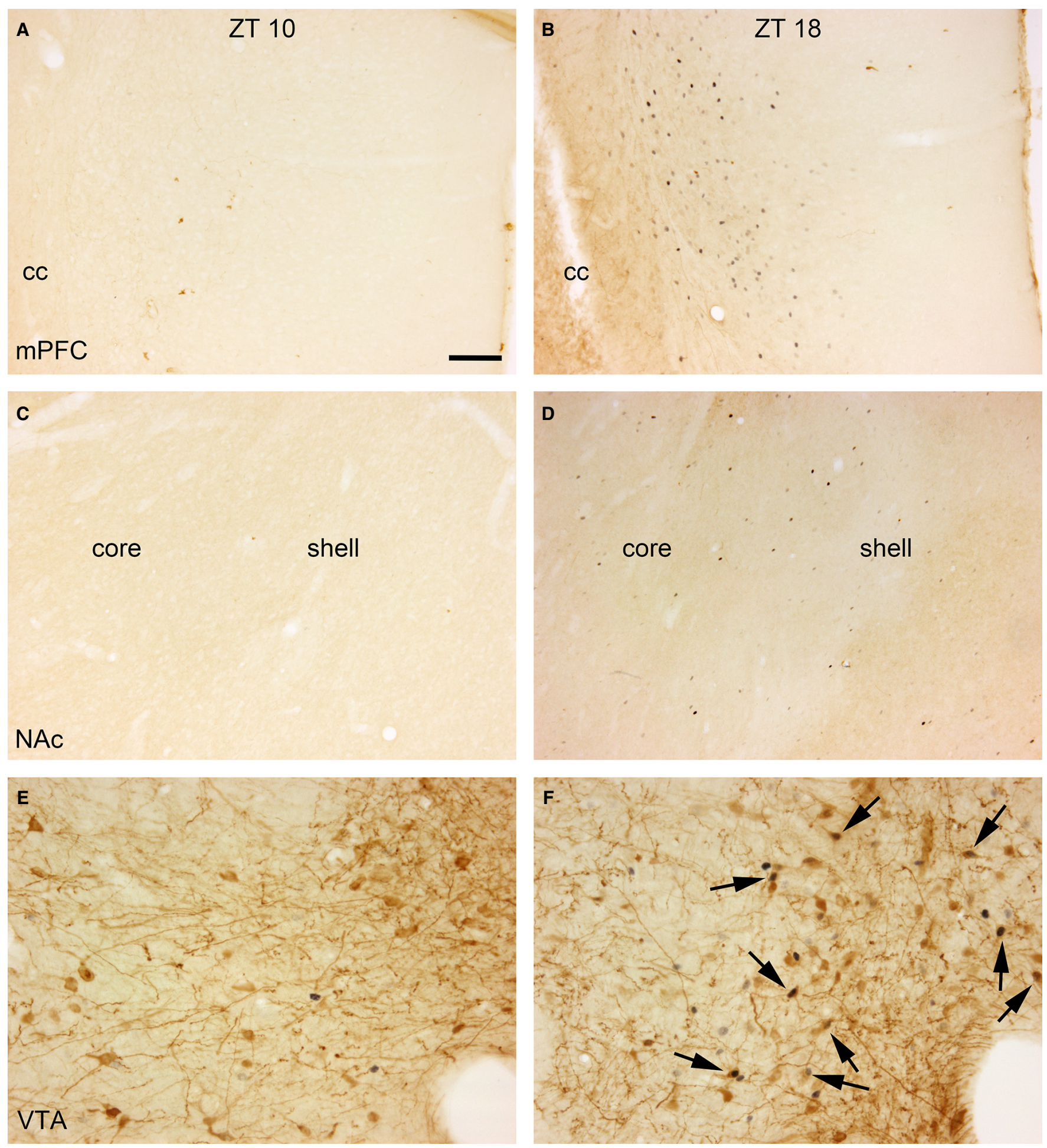

FIG. 2. cFos and TH immunoreactivity. Images showing cFos immunoreactivity (black) and TH immunoreactivity (brown) in the mPFC (prelimbic area), NAc (core and shell) and VTA in representative animals at ZT10 (A, C, and E) and ZT18 (B, D, and F). Arrows in F indicate cells co-expressing cFos and TH. Scale bars: $100 \mu \mathrm{m}(\mathrm{A}-\mathrm{D})$ or $50 \mu \mathrm{m}$ (E and F). cc, corpus callosum. [Color version of figure available online].

shell $\left(F_{1,19}=50.01, \quad P<0.0001\right)$ and core $\left(F_{1,19}=32.94\right.$, $P<0.0001)$. Post hoc analysis revealed that $\mathrm{mPFC}$ lesions reduced the number of cFos-IR cells at ZT18 (core, $P=0.0003$; shell, $P<0.0001)$, as compared with the sham group, and increased the number of cFos-IR cells at ZT10 in the shell $(P=0.019)$, but not in the core. Changes in the numbers of cFos-IR cells with mPFC lesions resulted in a loss of time-of-day differences in the NAc shell, and an attenuation of the difference in the NAc core (ZT10 vs. ZT18: $P=0.0258$ ). In contrast to the NAc, mPFC lesions did not affect the number of cFos-IR cells in the VTA, and a significant time of day difference was observed in lesioned rats (ZT10 vs. ZT18: $P<0.0001)$. Finally, sham treatment did not disrupt 

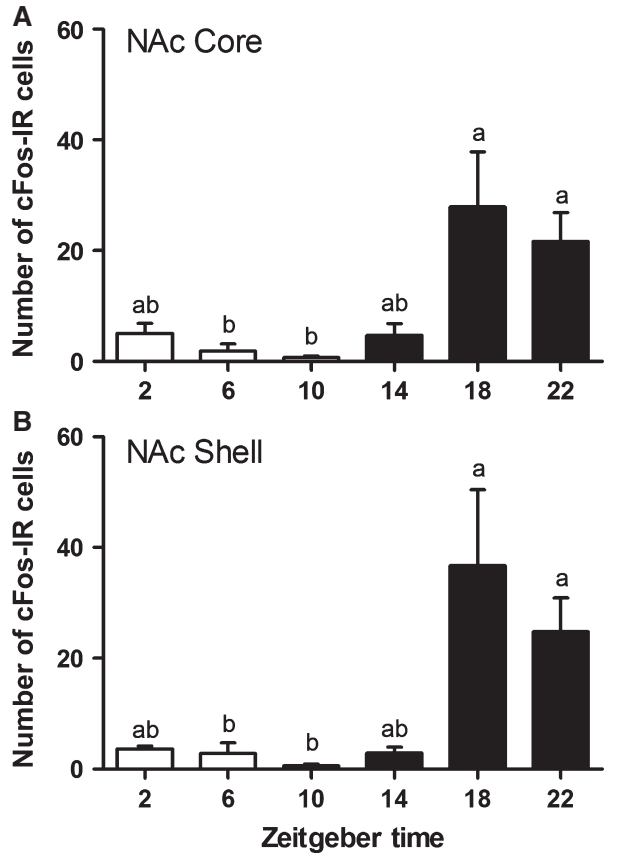

FIG. 3. Diurnal rhythms in cFos expression in the NAc: numbers of cFos-IR cells in the NAc core (A) and shell (B). Data are expressed as means $\pm \mathrm{SE}$ of the mean. The statistical relationship between the groups is indicated by lower-case letters; groups that share a common letter do not differ significantly.

diurnal rhythms in cFos immunoreactivity, and significant time-ofday differences were detected in the NAc core $(P<0.0001)$, NAc shell $(P<0.0001)$, and VTA $(P=0.0161)$, consistent with the findings described above. These results suggest that mPFC inputs mediate neural activation rhythms in the NAc, but not in the VTA.

\section{Discussion}

The current study demonstrated diurnal rhythms of neural activation in the VTA, NAc, and mPFC, which were generally elevated during the dark phase (ZT18-ZT22), and had nadirs during the end of the light phase (ZT10). In the VTA, this rhythm in neural activation was observed in both dopaminergic and non-dopaminergic cells. One major question arising from these observations concerns the origin of the signal driving these rhythms in neural activation. As both the NAc and the VTA receive glutamatergic inputs from the mPFC (Carr \& Sesack, 2000; Gabbott et al., 2005; Sesack \& Grace, 2010), we tested the hypothesis that mPFC inputs contribute to the observed neural activation rhythms. Indeed, ablation of the mPFC eliminated the diurnal rhythm in NAc cFos immunoreactivity by attenuating the peak expression at ZT18, but did not affect rhythms in VTA activity.

A comprehensive characterisation of the daily expression of $\mathrm{cFos}$ in the mesocorticolimbic reward system revealed diurnal rhythms, with peaks during the middle-end of the dark phase and nadirs during the end of the light phase, in the NAc, VTA, and mPFC, but not in the BLA or DG. Marginal rhythmicity was detected in the CeA. Although the expression of cFos is a useful indicator of neuronal activation, it is not always synonymous with membrane depolarisation, as dissociations have been observed between in vivo single-unit recordings and expression of cFos (Hoffman \& Lyo, 2002). Nonetheless, previous studies have also utilised cFos as a
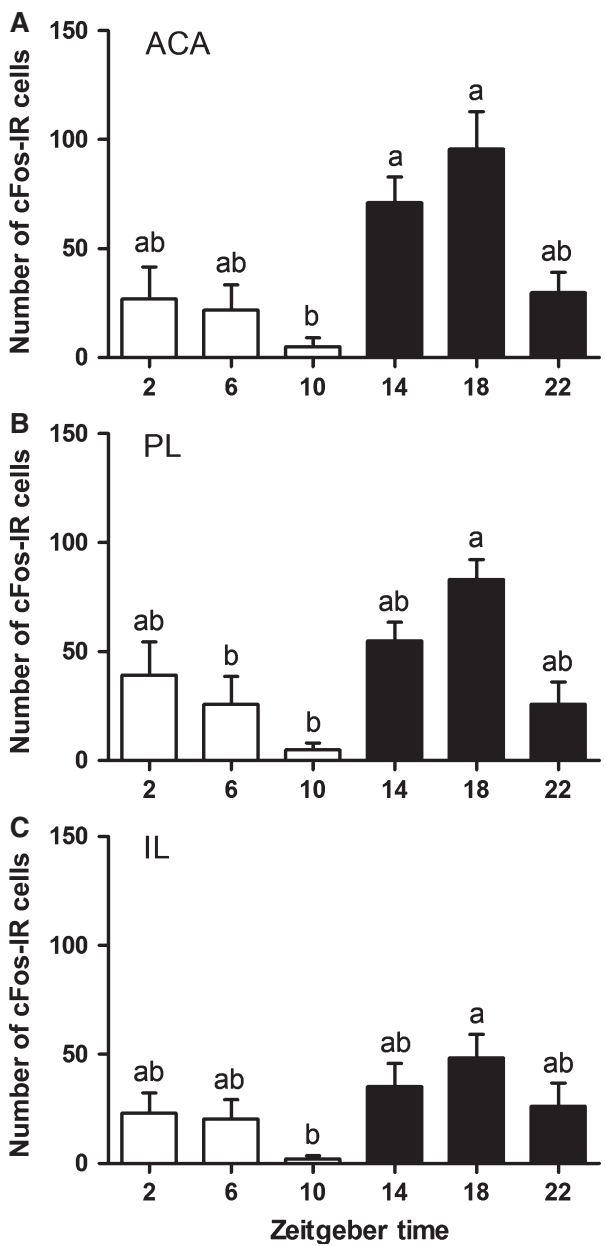

FIG. 4. Diurnal rhythms in cFos expression in the mPFC: numbers of cFosIR cells in the ACA (A), IL region (B), and PL region (C) of the mPFC. Data are expressed as means $\pm \mathrm{SE}$ of the mean. The statistical relationship between the groups is indicated by lower-case letters; groups that share a common letter do not differ significantly.
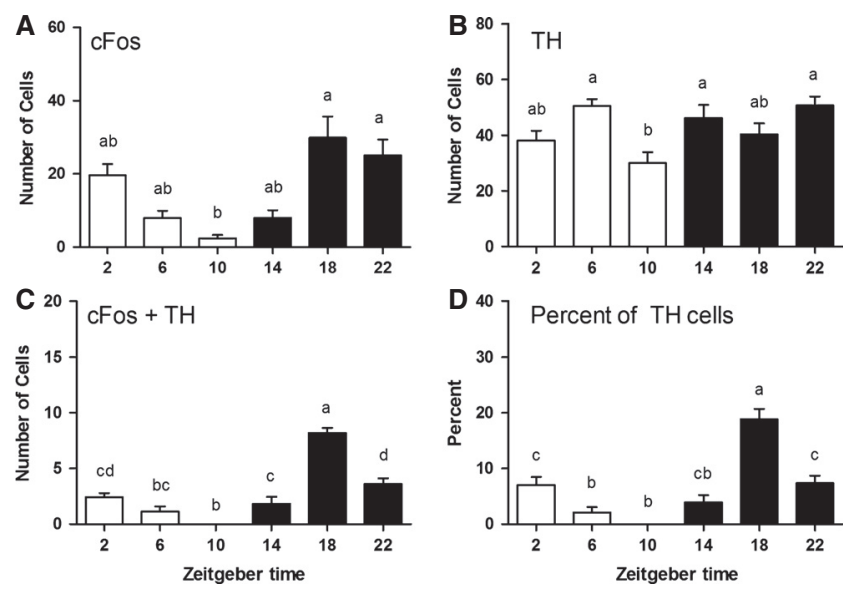

FIG. 5. Diurnal rhythms in cFos expression by dopaminergic and non-dopaminergic neurons in the VTA: diurnal variation in the numbers of cFos-IR cells (A), TH-IR cells (B), and dual cFos/TH-IR cells (C), and the percentage of TH cells co-expressing cFos (D), in the VTA. Data are expressed as mean number $\pm \mathrm{SE}$ of the mean. The statistical relationship between the groups is indicated by lower-case letters; groups that share a common letter do not differ significantly. 

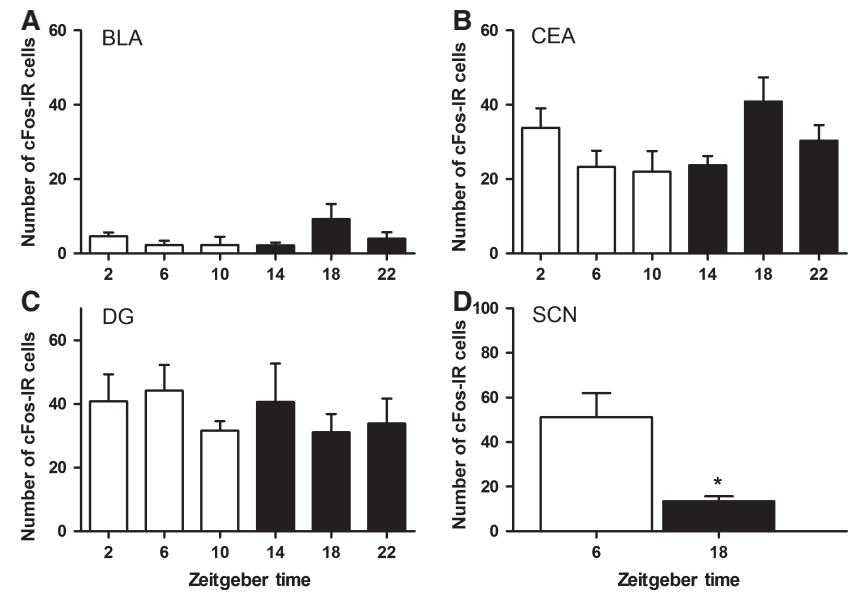

FIG. 6. Diurnal variation in neural activation in the amygdala, hippocampus and SCN: numbers of cFos-IR in the BLA (A), the CeA (B), the DG (C), and the SCN (D). Data are expressed as mean \pm SE of the mean. *Significant differences between time points.
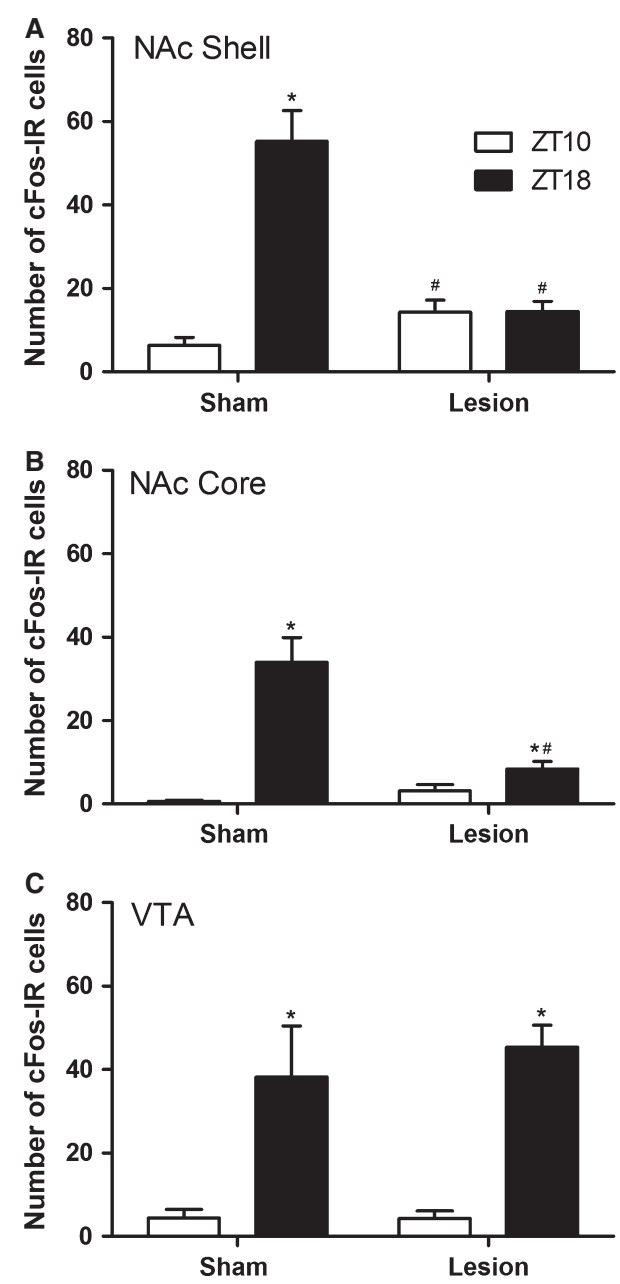

FIG. 7. The mPFC modulates neural activation in the mesolimbic reward system: effects of sham surgery and mPFC lesions on cFos immunoreactivity in the NAc core (A), NAc shell (B), and VTA (C). Data are expressed as mean $\pm \mathrm{SE}$ of the mean. *Significant effect of time of day within the treatment group. "Significant lesion effect within the time of day.

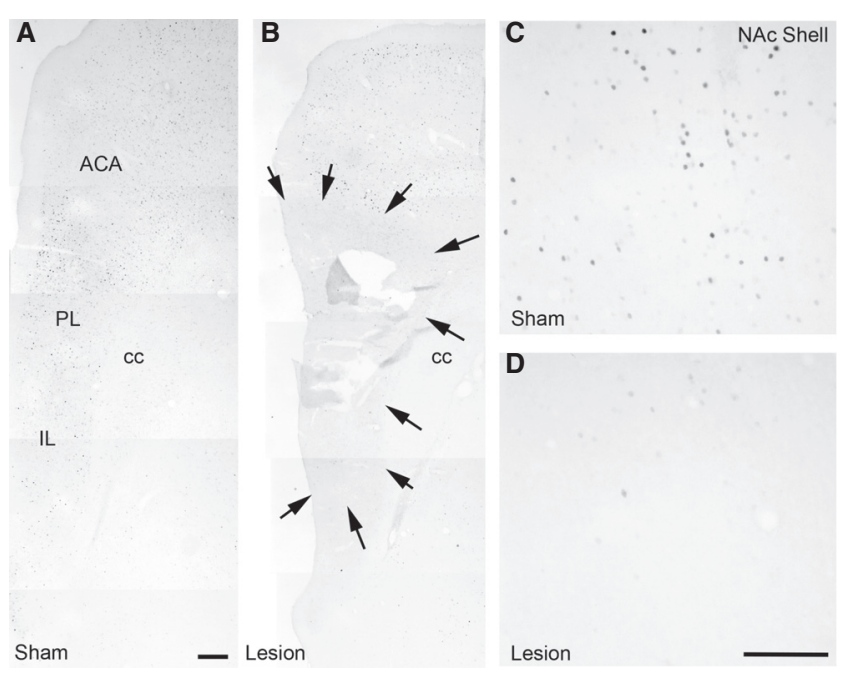

FIG. 8. cFos immunoreactivity in mPFC-lesioned brains: images showing the $\mathrm{mPFC}$ in representative sham (A) and lesioned (B) rats, in brain sections immunoprocessed for $\mathrm{cFos}$ immunoreactivity. Arrows in B indicate the extent of the lesion site encompassing the PL and IL regions, with sparing of the ACA. The images in $\mathrm{C}$ and $\mathrm{D}$ illustrate $\mathrm{cFos}$ immunoreactivity in the NAc shell at ZT18 in sham (C) and lesioned (D) rats. Scale bars: $250 \mu \mathrm{m}$ (A and B) or $100 \mu \mathrm{m}(\mathrm{C}$ and $\mathrm{D})$. cc, corpus callosum.

marker for daily changes in neural activation; however, these included only a few time points, or were limited to a particular portion of the day. Overall, the phases of these rhythms were consistent with our own observations. Specifically, a qualitative investigation of cFos protein expression during sleep and awake states reported peak cFos immunoreactivity at ZT18 (dark phase) as compared with ZT6-9 (light phase) in the frontal cortex and NAc (Pompeiano et al., 1994). Additionally, data from studies of food anticipatory behavior also showed rhythms in cFos immunoreactivity in the NAc and PFC, over a period of several hours (Angeles-Castellanos et al., 2007; Verwey et al., 2007). The absence of rhythms in neural activation in the DG and BLA under basal conditions suggests that these regions may not be involved in mediating rhythms in reward. However, there is evidence to support their role as accessory regions that are sensitive to the timing of rewards in the environment. Salient stimuli, such as palatable food and restricted feeding schedules, alter patterns of neural activation and clock gene expression throughout the reward system (Mendoza et al., 2005), and can generate rhythmicity in the DG and amygdala (Verwey et al., 2007). As these regions project to the mPFC, NAc, and VTA (Kelley, 2004), under these conditions they may convey timing information throughout the reward system and to other brain areas.

The mPFC, NAc and VTA are tightly interconnected, and form a major component of the neural circuits involved in motivation and reward (Kelley \& Berridge, 2002; Hyman et al., 2006). The finding that rhythms in neural activation are similar within this network forms the basis for several hypotheses regarding the generation of these activity rhythms. First, it is possible that glutamatergic and dopaminergic interconnections originating from the mPFC and VTA (Stuber et al., 2012) modulate the activity within this network. Indeed, a main finding of the current study is that mPFC inputs contribute to the diurnal rhythms in neural activation in the NAc, suggesting that these rhythms are influenced by glutamatergic mPFC outputs. These findings are consistent with previous reports of circadian rhythms in glutamate in the NAc or striatal dialysate (Marquez de Prado et al., 2000; Castaneda et al., 2004), with peaks around ZT18 and nadirs throughout the mid-light phase. 
Conversely, VTA rhythms were not dependent on mPFC inputs. Therefore, an alternative hypothesis is that rhythms in activation of VTA, mPFC and, potentially, NAc neurons instead derive from inputs from other brain areas, including the master circadian clock, the SCN, in the hypothalamus. The VTA is positioned to receive timing information from the $\mathrm{SCN}$ via two indirect circuits: one through the medial preoptic nucleus (Luo \& Aston-Jones, 2009), and the other by way of orexinergic neurons in the hypothalamus (Korotkova et al., 2003; Deurveilher \& Semba, 2005; Yoshida et al., 2006). There is currently little evidence to support a functional role of the former pathway, whereas the latter pathway appears to be ideally positioned to convey circadian information to the reward system. A large number of orexinergic efferents contact the VTA (Fadel \& Deutch, 2002), and, in addition to its familiar role in arousal and wakefulness (Sakurai, 2007), the orexin system has been implicated in the regulation of reward and addiction (Harris et al., 2005; Aston-Jones et al., 2009) via its role in mediating reward-induced activation of VTA dopaminergic neurons (Borgland et al., 2006; Zheng et al., 2007). The influence of orexinergic inputs on VTA dopamine activity fluctuates over the course of the day, with greater activation during the dark phase (Moorman \& AstonJones, 2010). Moreover, orexin neurons receive direct inputs from the SCN (Cutler et al., 1999; McGranaghan \& Piggins, 2001). Perturbations in SCN activity with phase shifting or SCN ablation alter (Akiyama et al., 2004; Zhang et al., 2004; Marston et al., 2008) the normal diurnal rhythms of orexin activation and signaling (Estabrooke et al., 2001; Lee et al., 2005). Interestingly, clock gene expression in forebrain regions is attenuated in mice lacking orexin neurons (Akiyama et al., 2004). Together, these findings suggest an integrated functional relationship between the circadian, orexigenic and reward systems.

Moorman \& Aston-Jones (2010) recently showed that the activity of VTA dopaminergic neurons during the dark phase is regulated by the $\mathrm{mPFC}$ and orexinergic afferents, with a gating role of orexin in enhancing mPFC excitatory control over dopaminergic neurons. Glutamatergic projections from the mPFC reach both dopaminergic and non-dopaminergic neurons of the VTA (Rossetti et al., 1998; Omelchenko \& Sesack, 2007). Modulation of corticolimbic glutamatergic inputs by orexin has been suggested to occur via increased $N$ methyl-D-aspartate receptor trafficking (Borgland et al., 2006) and via orexin receptor-mediated changes in phosphoinositol signaling (Moorman \& Aston-Jones, 2010). In the current study, we did not observe an effect of mPFC lesions on peak expression of VTA neural activity, suggesting that $\mathrm{mPFC}$ inputs did not make a major contribution to baseline excitation. However, it is possible that orexin inputs in mPFC-lesioned animals are sufficient to maintain the VTA activity rhythms.

We hypothesised that the observed rhythms in neural activation in the NAc and mPFC were, in part, mediated by dopamine originating from the VTA. Indeed, a diurnal pattern of activated dopaminergic cells was evident in the VTA, consistent with the neural activation rhythms observed in the NAc and mPFC. Dopaminergic afferents to the mPFC primarily originate from the VTA (Kelley \& Berridge, 2002; Sesack \& Grace, 2010), and may be responsible for conveying timing information to the mPFC, and thus indirectly to the NAc. A significant time-of-day effect has been previously reported in mPFC dopamine clearance, a measure of synaptic dopamine (Sleipness et al., 2008). The rhythm in PFC dopamine clearance is consistent with the pattern in VTA dopaminergic activity (Webb et al., 2009), with a peak at ZT4 and a nadir at ZT12. However, the dopamine clearance rhythm does not match the rhythm in cFos activity, and thus may not be causing the rhythms in neural activation. In addition, a subportion of the rhythmic cFos immunoreactivity in the VTA neurons may be glutamatergic. Luo et al. (2008) have reported that VTA neurons that fire selectively during the active night phase express mRNA for the glutamate cell marker vesicular glutamate transporter 2, and account for $14 \%$ of all active cells during the dark phase. Moreover, a subset of dopaminergic neurons also synthesise glutamate and release it into the NAc (Tecuapetla et al., 2010). These findings suggest that VTA neural activation may contribute to rhythms in the NAc and mPFC, via release of glutamate and/or dopamine.

A final hypothesis for the generation of neural activation rhythms in the mPFC, VTA and NAc is that these originate from oscillations in core circadian clock genes. Clock genes have been localised to many reward-related brain areas (McClung et al., 2005; Angeles-Castellanos et al., 2007; Verwey et al., 2007; Webb et al., 2009; Ramanathan et al., 2010), and oscillate in the NAc and mPFC (Angeles-Castellanos et al., 2007), but do not appear to be rhythmically expressed in the VTA (Webb et al., 2009). It is clear that clock genes play a role in regulating reward, as clock gene disruptions alter typical behavioral responses to drugs of abuse. For instance, periodl knockout mice show increased cocaine conditioned place preference (Abarca et al., 2002); intracerebroventricular injections of a DNAzyme that interferes with Period1 impairs morphine conditioned place preference (Liu et al., 2005); period 2 mutant mice show increased alcohol consumption (Brager et al., 2011); and mice lacking a functional clock gene are hypersensitive to cocaine (McClung et al., 2005). Clock gene disruptions also affect the normal functioning of the reward system. For instance, clock gene knockout mice have increased excitability of dopamine neurons and increased TH expression in the VTA (McClung et al., 2005); Period2 knockout mice show altered dopamine activity, with decreased transcription of the monoamine oxidase gene throughout the mesolimbic dopamine system, increased extracellular levels of dopamine, and altered neural activity in the striatum (Hampp et al., 2008); VTA-specific knockdown of clock genes in mice results in increased dopamine cell firing and altered expression of genes associated with reward, such as increased expression of the genes encoding $\mathrm{TH}$, dopamine receptor, and Homer2, and decreased expression of the genes encoding ionotropic glutamate receptor subunit 2 and dopamine $\beta$-hydroxylase (Mukherjee et al., 2010). The necessity of mesolimbic clock gene oscillations for rhythms in reward-related behaviors remains to be determined.

In summary, the current study demonstrates diurnal rhythms in neural activation in areas within the mesolimbic pathway, with a causal role for mPFC outputs in the generation of such rhythms in the NAc. These neural activation rhythms, in turn, may regulate diurnal differences in reward behaviors. The nadir in cFos immunoreactivity during the late light phase coincides with a nadir in the expression of psychostimulant reward (Roberts \& Andrews, 1997; Baird \& Gauvin, 2000; Roberts et al., 2002; Webb et al., 2009), whereas the peak in cFos expression correlates with high expression of reward for sexual behaviors (Webb et al., 2009). Future studies will be needed to determine whether these neural activation rhythms are, indeed, critical for rhythmic reward behavior.

\section{Acknowledgements}

We acknowledge Dr Michael Lehman for helpful discussions and valuable input. This research was supported by NSERC (R. M. Baltazar) and CIHR (I. C. Webb and L. M. Coolen) awards. The authors have no competing interests to declare. 


\section{Abbreviations}

$\mathrm{ABC}$, avidin-biotin-horseradish peroxidase complex; ACA, anterior cingulate area; BLA, basolateral amgydala; CeA, central amgydala; DAB, diaminobenzidene; DG, dentate gyrus; IL, infralimbic; IR, immunoreactive; mPFC, medial prefrontal cortex; NAc, nucleus accumbens; PB, phosphate buffer; PBS, phosphate-buffered saline; PL, prelimbic; SCN, suprachiasmatic nucleus; TH, tyrosine hydroxylase; VTA, ventral tegmental area; ZT, zeitgeber time.

\section{References}

Abarca, C., Albrecht, U. \& Spanagel, R. (2002) Cocaine sensitization and reward are under the influence of circadian genes and rhythm. Proc. Natl. Acad. Sci. USA, 99, 9026-9030.

Akiyama, M., Yuasa, T., Hayasaka, N., Horikawa, K., Sakurai, T. \& Shibata, S. (2004) Reduced food anticipatory activity in genetically orexin (hypocretin) neuron-ablated mice. Eur. J. Neurosci., 20, 3054-3062.

Angeles-Castellanos, M., Mendoza, J. \& Escobar, C. (2007) Restricted feeding schedules phase shift daily rhythms of c-Fos and protein Per1 immunoreactivity in corticolimbic regions in rats. Neuroscience, 144, 344-355.

Aston-Jones, G., Smith, R.J., Moorman, D.E. \& Richardson, K.A. (2009) Role of lateral hypothalamic orexin neurons in reward processing and addiction. Neuropharmacology, 56(Suppl 1), 112-121.

Baird, T.J. \& Gauvin, D. (2000) Characterization of cocaine self-administration and pharmacokinetics as a function of time of day in the rat. Pharmacol. Biochem. Be., 65, 289-299.

Balfour, M.E., Yu, L. \& Coolen, L.M. (2004) Sexual behavior and sex-associated environmental cues activate the mesolimbic system in male rats. Neuropsychopharmacol., 29, 718-730.

Balfour, M.E., Brown, J.L., Yu, L. \& Coolen, L.M. (2006) Potential contributions of efferents from medial prefrontal cortex to neural activation following sexual behavior in the male rat. Neuroscience, 137, 1259-1276.

Bentivogolio, M. \& Grass-Zucconi, G. (Eds) (1999) Immediate Early Gene Expression in Sleep and Wakefulness. CRC Press, Danvers, MA.

Borgland, S.L., Taha, S.A., Sarti, F., Fields, H.L. \& Bonci, A. (2006) Orexin $A$ in the VTA is critical for the induction of synaptic plasticity and behavioral sensitization to cocaine. Neuron, 49, 589-601.

Brager, A.J., Prosser, R.A. \& Glass, J.D. (2011) Circadian and acamprosate modulation of elevated ethanol drinking in mPer2 clock gene mutant mice. Chronobiol. Int., 28, 664-672.

Carr, D.B. \& Sesack, S.R. (1999) Terminals from the rat prefrontal cortex synapse on mesoaccumbens VTA neurons. Ann. NY Acad. Sci., 877, 676678.

Carr, D.B. \& Sesack, S.R. (2000) Projections from the rat prefrontal cortex to the ventral tegmental area: target specificity in the synaptic associations with mesoaccumbens and mesocortical neurons. J. Neurosci., 20, 3864 3873.

Castaneda, T.R., de Prado, B.M., Prieto, D. \& Mora, F. (2004) Circadian rhythms of dopamine, glutamate and GABA in the striatum and nucleus accumbens of the awake rat: modulation by light. J. Pineal Res., 36, 177185.

Champagne, F.A., Chretien, P., Stevenson, C.W., Zhang, T.Y., Gratton, A. \& Meaney, M.J. (2004) Variations in nucleus accumbens dopamine associated with individual differences in maternal behavior in the rat. J. Neurosci., 24, 4113-4123.

Cutler, D.J., Morris, R., Sheridhar, V., Wattam, T.A., Holmes, S., Patel, S., Arch, J.R., Wilson, S., Buckingham, R.E., Evans, M.L., Leslie, R.A. \& Williams, G. (1999) Differential distribution of orexin-A and orexin-B immunoreactivity in the rat brain and spinal cord. Peptides, 20, 14551470 .

Deurveilher, S. \& Semba, K. (2005) Indirect projections from the suprachiasmatic nucleus to major arousal-promoting cell groups in rat: implications for the circadian control of behavioural state. Neuroscience, 130, $165-183$.

Di Chiara, G. \& Imperato, A. (1988) Drugs abused by humans preferentially increase synaptic dopamine concentrations in the mesolimbic system of freely moving rats. Proc. Natl. Acad. Sci. USA, 85, 5274-5278.

Dominguez, J.M., Balfour, M.E., Lee, H.S., Brown, J.L., Davis, B.A. \& Coolen, L.M. (2007) Mating activates NMDA receptors in the medial preoptic area of male rats. Behav. Neurosci., 121, 1023-1031.

Estabrooke, I.V., McCarthy, M.T., Ko, E., Chou, T.C., Chemelli, R.M., Yanagisawa, M., Saper, C.B. \& Scammell, T.E. (2001) Fos expression in orexin neurons varies with behavioral state. J. Neurosci., 21, 1656-1662.
Fadel, J. \& Deutch, A.Y. (2002) Anatomical substrates of orexin-dopamine interactions: lateral hypothalamic projections to the ventral tegmental area. Neuroscience, 111, 379-387.

Frohmader, K.S., Pitchers, K.K., Balfour, M.E. \& Coolen, L.M. (2010a) Mixing pleasures: review of the effects of drugs on sex behavior in humans and animal models. Horm. Behav., 58, 149-162.

Frohmader, K.S., Wiskerke, J., Wise, R.A., Lehman, M.N. \& Coolen, L.M. (2010b) Methamphetamine acts on subpopulations of neurons regulating sexual behavior in male rats. Neuroscience, 166, 771-784.

Gabbott, P.L., Warner, T.A., Jays, P.R., Salway, P. \& Busby, S.J. (2005) Prefrontal cortex in the rat: projections to subcortical autonomic, motor, and limbic centers. J. Comp. Neurol., 492, 145-177.

Hampp, G., Ripperger, J.A., Houben, T., Schmutz, I., Blex, C., PerreauLenz, S., Brunk, I., Spanagel, R., Ahnert-Hilger, G., Meijer, J.H. \& Albrecht, U. (2008) Regulation of monoamine oxidase A by circadian-clock components implies clock influence on mood. Curr. Biol., 18, 678-683.

Harris, G.C., Wimmer, M. \& Aston-Jones, G. (2005) A role for lateral hypothalamic orexin neurons in reward seeking. Nature, 437, 556-559.

Hoffman, G.E. \& Lyo, D. (2002) Anatomical markers of activity in neuroendocrine systems: are we all 'fos-ed out'? J. Neuroendocrinol., 14, 259268.

Hyman, S.E., Malenka, R.C. \& Nestler, E.J. (2006) Neural mechanisms of addiction: the role of reward-related learning and memory. Annu. Rev. Neurosci., 29, 565-598.

Ikemoto, S. (2007) Dopamine reward circuitry: two projection systems from the ventral midbrain to the nucleus accumbens-olfactory tubercle complex. Brain Res. Rev., 56, 27-78.

Kelley, A.E. (2004) Memory and addiction: shared neural circuitry and molecular mechanisms. Neuron, 44, 161-179.

Kelley, A.E. \& Berridge, K.C. (2002) The neuroscience of natural rewards: relevance to addictive drugs. J. Neurosci., 22, 3306-3311.

Korotkova, T.M., Sergeeva, O.A., Eriksson, K.S., Haas, H.L. \& Brown, R.E. (2003) Excitation of ventral tegmental area dopaminergic and nondopaminergic neurons by orexins/hypocretins. J. Neurosci., 23, 7-11.

Kurtuncu, M., Arslan, A.D., Akhisaroglu, M., Manev, H. \& Uz, T. (2004) Involvement of the pineal gland in diurnal cocaine reward in mice. Eur. J. Pharmacol., 489, 203-205.

Lee, M.G., Hassani, O.K. \& Jones, B.E. (2005) Discharge of identified orexin/hypocretin neurons across the sleep-waking cycle. J. Neurosci., 25, 6716-6720.

Liu, Y., Wang, Y., Wan, C., Zhou, W., Peng, T., Wang, Z., Li, G., Cornelisson, G. \& Halberg, F. (2005) The role of mPer1 in morphine dependence in mice. Neuroscience, 130, 383-388.

Luo, A.H. \& Aston-Jones, G. (2009) Circuit projection from suprachiasmatic nucleus to ventral tegmental area: a novel circadian output pathway. Eur. J. Neurosci., 29, 748-760.

Luo, A.H., Georges, F.E. \& Aston-Jones, G.S. (2008) Novel neurons in ventral tegmental area fire selectively during the active phase of the diurnal cycle. Eur. J. Neurosci., 27, 408-422.

Marquez de Prado, B., Castaneda, T.R., Galindo, A., del Arco, A., Segovia, G., Reiter, R.J. \& Mora, F. (2000) Melatonin disrupts circadian rhythms of glutamate and GABA in the neostriatum of the aware rat: a microdialysis study. J. Pineal Res., 29, 209-216.

Marston, O.J., Williams, R.H., Canal, M.M., Samuels, R.E., Upton, N. \& Piggins, H.D. (2008) Circadian and dark-pulse activation of orexin/hypocretin neurons. Mol. Brain, 1, 19.

Martel, P. \& Fantino, M. (1996) Influence of the amount of food ingested on mesolimbic dopaminergic system activity: a microdialysis study. Pharmacol. Biochem. Be., 55, 297-302.

Martinez, G.S., Smale, L. \& Nunez, A.A. (2002) Diurnal and nocturnal rodents show rhythms in orexinergic neurons. Brain Res., 955, 1-7.

McClung, C.A., Sidiropoulou, K., Vitaterna, M., Takahashi, J.S., White, F.J., Cooper, D.C. \& Nestler, E.J. (2005) Regulation of dopaminergic transmission and cocaine reward by the Clock gene. Proc. Natl. Acad. Sci. USA, 102, 9377-9381.

McGranaghan, P.A. \& Piggins, H.D. (2001) Orexin A-like immunoreactivity in the hypothalamus and thalamus of the Syrian hamster (Mesocricetus auratus) and Siberian hamster (Phodopus sungorus), with special reference to circadian structures. Brain Res., 904, 234-244.

Mendoza, J., Angeles-Castellanos, M. \& Escobar, C. (2005) Entrainment by a palatable meal induces food-anticipatory activity and c-Fos expression in reward-related areas of the brain. Neuroscience, 133, 293-303.

Moorman, D.E. \& Aston-Jones, G. (2010) Orexin/hypocretin modulates response of ventral tegmental dopamine neurons to prefrontal activation: diurnal influences. J. Neurosci., 30, 15585-15599. 
Mukherjee, S., Coque, L., Cao, J.L., Kumar, J., Chakravarty, S., Asaithamby, A., Graham, A., Gordon, E., Enwright, J.F. III, Dileone, R.J., Birnbaum, S.G., Cooper, D.C. \& McClung, C.A. (2010) Knockdown of Clock in the ventral tegmental area through RNA interference results in a mixed state of mania and depression-like behavior. Biol. Psychiat., 68, 503-511.

Noel, M.B. \& Wise, R.A. (1995) Ventral tegmental injections of a selective mu or delta opioid enhance feeding in food-deprived rats. Brain Res., 673, 304-312.

Numan, M., Bress, J.A., Ranker, L.R., Gary, A.J., Denicola, A.L., Bettis, J.K. \& Knapp, S.E. (2010) The importance of the basolateral/basomedial amygdala for goal-directed maternal responses in postpartum rats. Behav. Brain Res., 214, 368-376.

Omelchenko, N. \& Sesack, S.R. (2007) Glutamate synaptic inputs to ventral tegmental area neurons in the rat derive primarily from subcortical sources. Neuroscience, 146, 1259-1274.

Pfaus, J.G., Damsma, G., Nomikos, G.G., Wenkstern, D.G., Blaha, C.D., Phillips, A.G. \& Fibiger, H.C. (1990) Sexual behavior enhances central dopamine transmission in the male rat. Brain Res., 530, 345-348.

Pitchers, K.K., Balfour, M.E., Lehman, M.N., Richtand, N.M., Yu, L. \& Coolen, L.M. (2010) Neuroplasticity in the mesolimbic system induced by natural reward and subsequent reward abstinence. Biol. Psychiat., 67, 872879.

Pompeiano, M., Cirelli, C. \& Tononi, G. (1994) Immediate-early genes in spontaneous wakefulness and sleep: expression of c-fos and NGFI-A mRNA and protein. J. Sleep Res., 3, 80-96.

Pompeiano, M., Cirelli, C., Arrighi, P. \& Tononi, G. (1995) c-Fos expression during wakefulness and sleep. Neurophysiol. Clin., 25, 329-341.

Ramanathan, C., Stowie, A., Smale, L. \& Nunez, A. (2010) PER2 rhythms in the amygdala and bed nucleus of the stria terminalis of the diurnal grass rat (Arvicanthis niloticus). Neurosci. Lett., 473, 220-223.

Roberts, D.C. \& Andrews, M.M. (1997) Baclofen suppression of cocaine self-administration: demonstration using a discrete trials procedure. Psychopharmacology, 131, 271-277.

Roberts, D.C., Brebner, K., Vincler, M. \& Lynch, W.J. (2002) Patterns of cocaine self-administration in rats produced by various access conditions under a discrete trials procedure. Drug Alcohol Depen., 67, 291-299.

Rossetti, Z.L., Marcangione, C. \& Wise, R.A. (1998) Increase of extracellular glutamate and expression of Fos-like immunoreactivity in the ventral tegmental area in response to electrical stimulation of the prefrontal cortex. J. Neurochem., 70, 1503-1512.

Sakurai, T. (2007) The neural circuit of orexin (hypocretin): maintaining sleep and wakefulness. Nat. Rev. Neurosci., 8, 171-181.

Schwartz, W.J., Carpino, A. Jr., de la Iglesia, H.O., Baler, R., Klein, D.C., Nakabeppu, Y. \& Aronin, N. (2000) Differential regulation of Fos family genes in the ventrolateral and dorsomedial subdivisions of the rat suprachiasmatic nucleus. Neuroscience, 98, 535-547.

Sesack, S.R. \& Grace, A.A. (2010) Cortico-basal ganglia reward network: microcircuitry. Neuropsychopharmacol., 35, 27-47.

Sleipness, E.P., Sorg, B.A. \& Jansen, H.T. (2007) Diurnal differences in dopamine transporter and tyrosine hydroxylase levels in rat brain: dependence on the suprachiasmatic nucleus. Brain Res., 1129, 34-42.
Sleipness, E.P., Jansen, H.T., Schenk, J.O. \& Sorg, B.A. (2008) Time-of-day differences in dopamine clearance in the rat medial prefrontal cortex and nucleus accumbens. Synapse, 62, 877-885.

Spanagel, R. \& Weiss, F. (1999) The dopamine hypothesis of reward: past and current status. Trends Neurosci., 22, 521-527.

Stuber, G.D., Britt, J.P. \& Bonci, A. (2012) Optogenetic modulation of neural circuits that underlie reward seeking. Biol. Psychiat., 71, 1061-1067.

Swanson, L.W. (Ed.) (1998) Brain Maps: Structure of the Rat Brain. Elsevier, Amsterdam.

Tecuapetla, F., Patel, J.C., Xenias, H., English, D., Tadros, I., Shah, F., Berlin, J., Deisseroth, K., Rice, M.E., Tepper, J.M. \& Koos, T. (2010) Glutamatergic signaling by mesolimbic dopamine neurons in the nucleus accumbens. J. Neurosci, 30, 7105-7110.

Thomas, M.J., Kalivas, P.W. \& Shaham, Y. (2008) Neuroplasticity in the mesolimbic dopamine system and cocaine addiction. Brit. J. Pharmacol., 154, 327-342.

Vanhoutte, P., Barnier, J.V., Guibert, B., Pages, C., Besson, M.J., Hipskind, R.A. \& Caboche, J. (1999) Glutamate induces phosphorylation of Elk-1 and CREB, along with c-fos activation, via an extracellular signal-regulated kinase-dependent pathway in brain slices. Mol. Cell. Biol., 19, 136146.

Verwey, M., Khoja, Z., Stewart, J. \& Amir, S. (2007) Differential regulation of the expression of Period2 protein in the limbic forebrain and dorsomedial hypothalamus by daily limited access to highly palatable food in food-deprived and free-fed rats. Neuroscience, 147, 277-285.

Watson, R.E. Jr., Wiegand, S.J., Clough, R.W. \& Hoffman, G.E. (1986) Use of cryoprotectant to maintain long-term peptide immunoreactivity and tissue morphology. Peptides, 7, 155-159.

Webb, I.C., Baltazar, R.M., Wang, X., Pitchers, K.K., Coolen, L.M. \& Lehman, M.N. (2009) Diurnal variations in natural and drug reward, mesolimbic tyrosine hydroxylase, and clock gene expression in the male rat. J. Biol. Rhythm., 24, 465-476.

Wise, R.A. (2004) Dopamine, learning and motivation. Nat. Rev. Neurosci., 5, 483-494.

Wolf, M.E., Sun, X., Mangiavacchi, S. \& Chao, S.Z. (2004) Psychomotor stimulants and neuronal plasticity. Neuropharmacology, 47(Suppl 1), 61-

Xia, Z., Dudek, H., Miranti, C.K. \& Greenberg, M.E. (1996) Calcium influx via the NMDA receptor induces immediate early gene transcription by a MAP kinase/ERK-dependent mechanism. J. Neurosci., 16, $5425-5436$.

Yoshida, K., McCormack, S., Espana, R.A., Crocker, A. \& Scammell, T.E (2006) Afferents to the orexin neurons of the rat brain. J. Comp. Neurol., 494, 845-861.

Zhang, S., Zeitzer, J.M., Yoshida, Y., Wisor, J.P., Nishino, S., Edgar, D.M \& Mignot, E. (2004) Lesions of the suprachiasmatic nucleus eliminate the daily rhythm of hypocretin-1 release. Sleep, 27, 619-627.

Zheng, H., Patterson, L.M. \& Berthoud, H.R. (2007) Orexin signaling in the ventral tegmental area is required for high-fat appetite induced by opioid stimulation of the nucleus accumbens. J. Neurosci., 27, 1107511082 . 